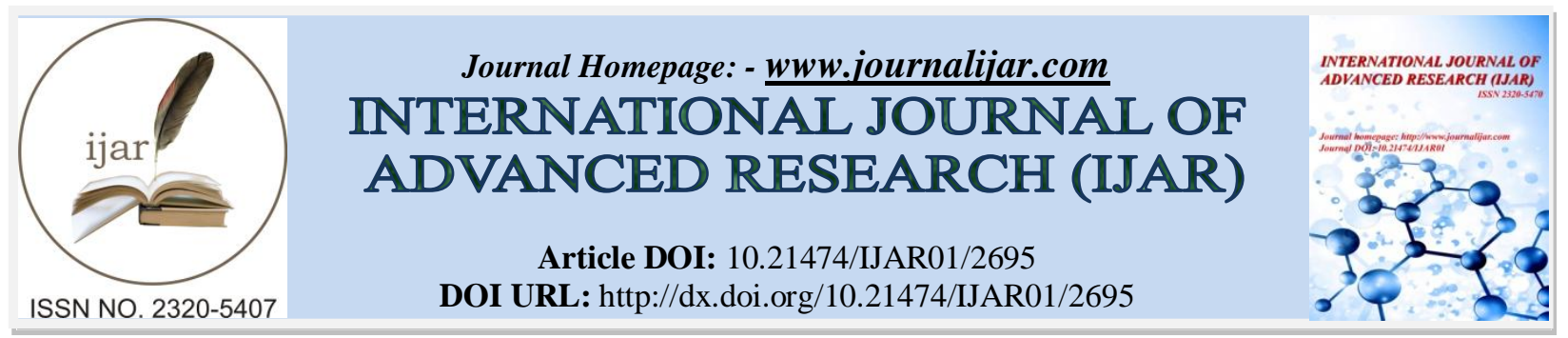

\title{
RESEARCH ARTICLE \\ EFFECT OF DISCUSSING FRAMINGHAM RISK SCORE ON SMOKE CESSATION: PILOT RANDOMIZED CLINICAL TRIAL
}

\author{
Amr Jamal, Abdullah Alrajhi, Abdullah Aldubaib, Abdulaziz Alsuwailem, Rayan Alzuhairi and Abdulaziz \\ Alonazy.
}

\section{Manuscript Info}

\section{Manuscript History}

Received: 31 October 2016

Final Accepted: 01 December 2016

Published: December 2016

Key words:-

Framingham score, smoking, cessation, cardiovascular disease, clinical trial, Saudi Arabia.

\section{Abstract}

Introduction: Smoking has an obvious effect on cardiovascular diseases. We tried to find an effective way for smoking cessation strategy.Our aim was to determine the probability of smokingcessationafter discussing cardiovascular risk with and without smoking during family medicine clinic visits using the Framingham score.

Methods: Randomized controlled clinical trial was conducted at family medicine outpatient clinics in two hospitals in Riyadh, Saudi Arabia. Sixty-four participants were recruited in to the study and were randomized into two arms: Framingham score (experimental) and traditional (control) groups.Allocation was concealed. There were three follow up sessions, once every two weeks. Structured interviews were used to fill validated questionnaire in each follow up.

Result: We found $(4 / 25 ; 16 \%)$ participants quit smoking in the intervention group, while only $(2 / 30 ; 16 \%)$ participants in control group quit smoking after six-week follow up $(\mathrm{P}$-value $=0.251)$. However, $(13 / 25 ; 52 \%)$ (number of cigarettes) on the intervention group and $(19 / 30 ; 63 \%)$ patients on the control group reduced the number of consumed cigarettes after six-week follow up.

Conclusione: We thought the Framingham score advice will be more beneficial to smokers, but the result showed no significant difference.

Copy Right, IJAR, 2016,. All rights reserved.

\section{Introduction:-}

Smoking is one of the most important risk factors for cardiovascular disease, and can cause peripheral arterial disease and coronary artery disease in high risk persons. A previous study showed $65 \%$ reduction in myocardial infarction risk when a person stops smoking. [11]

The Framingham score which predict the riskprobability of CVD depends depending on several factors, including smoking.[10]

In 2009, the prevalence of smoking in Saudi Arabia among general population ranged from $2.4 \%$ to 52.3\%. Among school students, it ranged from $12 \%$ to $29.8 \%$, among university students it ranged from $2.4 \%$ to $37 \%$, and among adults it ranged from $11.6 \%$ to $52.3 \%$. In elderly people, it was $25 \%$. In males, it ranged from $13 \%$ to $38 \%$, while in females it ranged from $1 \%$ to $16 \%$. It is obvious that smoking is quite prevalent in the Saudi population among various age groups. [12]. Globally, The prevalence of current smokers worldwide is higher in males than in females 
at different ages. For example, in China the prevalence was 59.3\% among men and $1.6 \%$ among women aged from 25 to 44 years. [13]

Increase in smoking prevalence and poor awareness of smoking risks are the most common causes of cardiovascular diseases in Saudi Arabia. As smoking is harmful to the person and the community, we tried to get the advantages from Framingham score system that may help the smokers to quit smoking.

Our objective is to determine the probability of smoking cessation among smokers after discussing the cardiovascular risk with and without smoking during family medicine clinic visits using Framingham score, in comparison with the traditional way of quit smoking advice.

\section{Methodology:- \\ Study Design:-}

This is a randomized controlled clinical trial to evaluate the effectiveness of using Framingham risk score,Risk Assessment Tool for Estimating 10-years Risk of Having a Heart Attack among smokers for smoking cessation.[10]. The initial assessment questionnaire consisted of 24 questions covering the elements of a smoker's life. Seven of these questions were about demographic data. Then 16 questions about the status of smoking among smokers were designed initially by the authors and reviewed by some experts and the last question was about Framingham score for the patient with and without smoking. The date of next follow up was provided to all the participants. The follow up questionnaire had 6 questions to evaluate the effect of the counselling and to detect how many persons quitted smoking and the number consumed cigarettes per day for those who had not quit smoking. We called the participant for the follow up which was every two weeks for three times, we asked them about the effect of the advice by how many cigarettes decreased and smoking cessation.

\section{Participants:-}

The target population was 64 smokers who visited the family medicine clinics at King Khalid University Hospital in Riyadh, Saudi Arabia and Prince Mohammed Bin Abdulaziz Hospital in Riyadh, Saudi Arabia.

\section{Data collection:-}

The questionnaire was distributed to all patients in the clinic daily. In addition, researchers filled all questionnaires while they interviewed the smoker patients who fulfilled the inclusion criteria. The inclusioncriteria are (adult males - smoking at least 10 cigarettes per day - visiting family medicine clinic - patients who agree to enrolled in our research study). The exclusionCriteriaare (Females- over 80 - mental abnormalities or major psychiatric illness patients who have enrolled in smoking cessation programs for the last two months. For the interventional group, lab investigations were accessed along with blood pressure values to calculate their Framingham risk score through the website that measures the percentage of developing cardiovascular diseases for the next 10 years by inserting specific information (Age, Gender, LDL, Cholesterol, blood pressure and smoking). [10]We shared the results with the smoker patient and explained what the variables of this calculation meant, then recalculated his score if he quits smoking and showed him the difference between these two results to have an effect on him to quit smoking. While in the control group we used a standard traditional advice and a simple booklet. Then we compared the smoking cessation rate between these two groups to evaluated the effectiveness of the advice. The participation to this study was voluntary and anonymous. Data were collected from 1st December 2013 to 26th December 2013. Then we followed up the patients through phone calls 3 times, once every 2 weeks.

\section{Data analysis:-}

We used SPSS (Statistical Package for Social Sciences, IBM, New York, USA) software to analyze data. Following tests were used to compare the results between two groups: Mann Whitney U test, Chi Square test, Fisher's Exact test, Kruskal Wallis test, Wilcoxon Signed rank test, Cochran Q test. $\mathrm{p}<0.05$ was considered significant.

\section{Ethical statement:-}

The proposal of the study was reviewed and approved by students research committee. We contacted the family medicine department to get the ethical approval to apply our study to their patients. All data is maintained in a secure fashion. All data was analyzed as a total population considering that individual privacy is maintained. All records with the results and progress both electronic and written will be maintained with the researcher for a minimum period of five years in case of review. 


\section{Results:-}

We collected 64 responses during a period of four weeks. We excluded 8 patients because they did not meet our inclusion criteria and lost 9 patients during the follow up period. The total participants included in the analysis were 55. The participant who had affected by the advice through reduction in number of cigarettesin the intervention group was noted on $(13 / 25)$ patients $(52 \%)$ with $\mathrm{SD}=0.510$ and $(19 / 30)$ patients in the control group (63\%) with $\mathrm{SD}=0.507$ ( $\mathrm{p}=0.396$, calculated by Chi-square test).

There was no significance difference in smoking cessation between intervention group and the control group where $4(16 \%$, with $\mathrm{SD}=0.374)$ and $2(6.6 \%, \mathrm{SD}=0.254)$ patients respectively quite smoking $(\mathrm{p}=0.251$, calculated by Fisher's Exact Test). For comparison between Framingham score (with and without smoking); we used Wilcoxon signed rank test because the data were not normally distributed and were paired (Table 1). But the difference in Framingham score for subjects has no applicable effect on their smoking habit. On the contrary, 3 subjects from the intervention group and 5 subjects from the control group increased their cigarette consumption after the advice. For the number of cigarettes consumed daily,there was no difference between married and singles (Table 2)

\begin{tabular}{|c|c|c|c|c|c|}
\hline \multicolumn{6}{|c|}{ Occupation * Group Cross tabulation. } \\
\hline & & & \multicolumn{2}{|c|}{ Group } & \multirow[t]{2}{*}{ Total } \\
\hline & & & $\begin{array}{l}\text { Intervention } \\
\text { group }\end{array}$ & Control Group & \\
\hline \multirow[t]{10}{*}{ OccupGr } & \multirow[t]{2}{*}{ Office work Group } & Count & 12 & 16 & 28 \\
\hline & & $\%$ within Group & $48.0 \%$ & $53.3 \%$ & $50.9 \%$ \\
\hline & \multirow[t]{2}{*}{ Field work Group } & Count & 4 & 9 & 13 \\
\hline & & $\%$ within Group & $16.0 \%$ & $30.0 \%$ & $23.6 \%$ \\
\hline & \multirow[t]{2}{*}{ Military work Group } & Count & 3 & 3 & 6 \\
\hline & & $\%$ within Group & $12.0 \%$ & $10.0 \%$ & $10.9 \%$ \\
\hline & \multirow[t]{2}{*}{ Retired Group } & Count & 2 & 1 & 3 \\
\hline & & $\%$ within Group & $8.0 \%$ & $3.3 \%$ & $5.5 \%$ \\
\hline & \multirow[t]{2}{*}{ Unemployed } & Count & 4 & 1 & 5 \\
\hline & & $\%$ within Group & $16.0 \%$ & $3.3 \%$ & $9.1 \%$ \\
\hline \multirow{2}{*}{\multicolumn{2}{|c|}{ Total }} & Count & 25 & 30 & 55 \\
\hline & & $\%$ within Group & $100.0 \%$ & $100.0 \%$ & $100.0 \%$ \\
\hline
\end{tabular}

\begin{tabular}{|c|c|c|c|c|c|}
\hline \multicolumn{6}{|c|}{ Age Group * Group Cross tabulation } \\
\hline & & & \multicolumn{2}{|c|}{ Group } & \multirow[t]{2}{*}{ Total } \\
\hline & & & $\begin{array}{l}\text { Intervention } \\
\text { group }\end{array}$ & Control Group & \\
\hline \multirow[t]{6}{*}{ Age Group } & \multirow[t]{2}{*}{ Age from Lowest to 29} & Count & 12 & 11 & 23 \\
\hline & & \% within Group & $48.0 \%$ & $36.7 \%$ & $41.8 \%$ \\
\hline & \multirow[t]{2}{*}{ Age from 30 to 45} & Count & 9 & 17 & 26 \\
\hline & & \% within Group & $36.0 \%$ & $56.7 \%$ & $47.3 \%$ \\
\hline & \multirow[t]{2}{*}{ Age from 46 to highest } & Count & 4 & 2 & 6 \\
\hline & & \% within Group & $16.0 \%$ & $6.7 \%$ & $10.9 \%$ \\
\hline \multirow{2}{*}{\multicolumn{2}{|c|}{ Total }} & Count & 25 & 30 & 55 \\
\hline & & $\%$ within Group & $100.0 \%$ & $100.0 \%$ & $100.0 \%$ \\
\hline
\end{tabular}

\begin{tabular}{|c|c|c|c|c|c|}
\hline \multicolumn{9}{|c|}{ Patient Gender * Group Cross tabulation } \\
\hline \multicolumn{2}{|c|}{} & \multicolumn{2}{c|}{ Total } \\
\cline { 3 - 5 } & & $\begin{array}{c}\text { Intervention } \\
\text { group }\end{array}$ & Control Group & \\
\hline \multirow{2}{*}{ Patient Gender } & Male & Count & 24 & 30 & 54 \\
\cline { 3 - 6 } & & $\%$ within Group & $100.0 \%$ & $100.0 \%$ & $100.0 \%$ \\
\hline \multicolumn{2}{|c|}{ Total } & Count & 24 & 30 & 54 \\
\cline { 3 - 6 } & & $100.0 \%$ & $100.0 \%$ & $100.0 \%$ \\
\hline
\end{tabular}




\begin{tabular}{|c|c|c|c|c|c|}
\hline \multicolumn{6}{|c|}{ Level of patient's education * Group Cross tabulation } \\
\hline & & & \multicolumn{2}{|c|}{ Group } & \multirow[t]{2}{*}{ Total } \\
\hline & & & $\begin{array}{l}\text { Intervention } \\
\text { group }\end{array}$ & $\begin{array}{l}\text { Control } \\
\text { Group }\end{array}$ & \\
\hline \multirow{12}{*}{$\begin{array}{l}\text { Level of patient's } \\
\text { education }\end{array}$} & \multirow[t]{2}{*}{ Elementary School } & Count & 2 & 2 & 4 \\
\hline & & $\begin{array}{l}\% \text { within } \\
\text { Group }\end{array}$ & $8.0 \%$ & $6.7 \%$ & $7.3 \%$ \\
\hline & \multirow{2}{*}{$\begin{array}{c}\text { Intermediate } \\
\text { School }\end{array}$} & Count & 1 & 3 & 4 \\
\hline & & $\begin{array}{l}\% \text { within } \\
\text { Group }\end{array}$ & $4.0 \%$ & $10.0 \%$ & $7.3 \%$ \\
\hline & \multirow[t]{2}{*}{ High School } & Count & 12 & 15 & 27 \\
\hline & & $\begin{array}{l}\% \text { within } \\
\text { Group }\end{array}$ & $48.0 \%$ & $50.0 \%$ & $49.1 \%$ \\
\hline & \multirow[t]{2}{*}{ Bachelor } & Count & 6 & 6 & 12 \\
\hline & & $\begin{array}{l}\% \text { within } \\
\text { Group }\end{array}$ & $24.0 \%$ & $20.0 \%$ & $21.8 \%$ \\
\hline & \multirow[t]{2}{*}{ Master OR Phd } & Count & 0 & 1 & 1 \\
\hline & & $\begin{array}{l}\% \text { within } \\
\text { Group }\end{array}$ & $0.0 \%$ & $3.3 \%$ & $1.8 \%$ \\
\hline & \multirow[t]{2}{*}{ Other } & Count & 4 & 3 & 7 \\
\hline & & $\begin{array}{l}\% \text { within } \\
\text { Group }\end{array}$ & $16.0 \%$ & $10.0 \%$ & $12.7 \%$ \\
\hline \multirow{2}{*}{\multicolumn{2}{|c|}{ Total }} & Count & 25 & 30 & 55 \\
\hline & & $\begin{array}{l}\% \text { within } \\
\text { Group }\end{array}$ & $100.0 \%$ & $100.0 \%$ & $100.0 \%$ \\
\hline
\end{tabular}

\begin{tabular}{|c|c|c|c|c|c|}
\hline \multicolumn{9}{|c|}{ Patient Marital Status * Group Cross tabulation } \\
\hline \multicolumn{2}{|c|}{} & \multicolumn{2}{c|}{ Troup } & \multirow{2}{*}{ Total } \\
\cline { 3 - 5 } \multicolumn{2}{|c|}{} & $\begin{array}{c}\text { Intervention } \\
\text { group }\end{array}$ & Control Group & \\
\hline \multirow{2}{*}{ Patient Marital Status } & \multirow{2}{*}{ Single } & Count & 12 & 9 & 21 \\
\cline { 3 - 6 } & & $\%$ within Group & $48.0 \%$ & $30.0 \%$ & $38.2 \%$ \\
\cline { 2 - 5 } & \multirow{2}{*}{ Married } & Count & 13 & 21 & 34 \\
\cline { 3 - 6 } & & $\%$ within Group & $52.0 \%$ & $70.0 \%$ & $61.8 \%$ \\
\hline \multirow{2}{*}{ Total } & Count & 25 & 30 & 55 \\
\cline { 3 - 6 } & & $\%$ within Group & $100.0 \%$ & $100.0 \%$ & $100.0 \%$ \\
\hline
\end{tabular}

\begin{tabular}{|l|l|l|l|}
\hline \multicolumn{2}{|l|}{ Report } & \multicolumn{2}{|l|}{} \\
\hline \multirow{2}{*}{ Group } & Mean & $\begin{array}{l}\text { What is framingham } \\
\text { score with smoking }\end{array}$ & $\begin{array}{l}\text { What is framingham } \\
\text { score without smoking }\end{array}$ \\
\cline { 2 - 4 } & $\mathrm{N}$ & 9.56 & 4.32 \\
\cline { 2 - 4 } & Std. Deviation & 25 & 25 \\
\cline { 2 - 4 } & 12.946 & 8.716 \\
\hline
\end{tabular}

Table 1:- Framingham scores for the intervention group only.

\begin{tabular}{|l|l|l|}
\hline & Mean \pm Standard Deviation & p \\
\hline Before Quitting (i.e. with smoking) & $9.56 \pm 12.95$ & $\mathrm{p}<0.001$ \\
\cline { 1 - 2 } After Quitting (i.e. if they quit) & $4.32 \pm 8.72$ & \\
\hline
\end{tabular}


Table 2:- Daily cigarettes before the advice as a function of marital status. [It would be good if you can add data for after the advice also]

\begin{tabular}{|l|l|l|}
\hline Marital status & Number of cigarettes & \\
\hline Single & $21.2 \pm 8.7$ & $\mathrm{P}=0.539$ \\
\cline { 1 - 2 } Married & $19.8 \pm 9.7$ & \\
\hline
\end{tabular}

The p-value was calculated by Mann Whitney test $=0.539$

We also measured the effect of smoking cessation advice in relation to the educational level of the participants our results indicate no significant difference among various educational levels (Table 3).

Table No. 3:- Effect of advice vs. Education.

\begin{tabular}{|c|c|c|c|}
\hline & Effect & & \multirow{8}{*}{$p=0.298$} \\
\hline Education & No & Yes & \\
\hline Elementary school & $3(75 \%)$ & $1(25 \%)$ & \\
\hline Intermediate school & $0(0 \%)$ & $4(100 \%)$ & \\
\hline High School & $13(48.1 \%)$ & $14(51.9 \%)$ & \\
\hline Bachelors Degree & $4(33.3 \%)$ & $8(66.7 \%)$ & \\
\hline Masters Degree & $0(0 \%)$ & $1(100 \%)$ & \\
\hline Other & $3(42.9 \%)$ & $4(57 \%)$ & \\
\hline
\end{tabular}

We also measured the effect of smoking cessation advice in relation to duration at three follow up (by phone) (Table 4\&5). We found that effect was greater in at follow up 1 compared with others. It indicates that the effect of our advice faded away with the passage of time.

Table 4:- Number of cigarettes consumed daily by various age groups (as recorded during three follow ups).

\begin{tabular}{|c|c|c|c|c|c|c|}
\hline Age group & $\begin{array}{l}\text { Cigarettes } \\
\text { follow up 1 }\end{array}$ & & $\begin{array}{ll}\text { Cigarettes } \\
\text { follow up 2 }\end{array}$ & & $\begin{array}{l}\text { Cigarettes at follow } \\
\text { up } 3\end{array}$ & \\
\hline$<29$ Years & $16.96 \pm 9.1$ & \multirow{3}{*}{$\mathrm{p}=0.019$} & $16.64 \pm 9.8$ & \multirow{3}{*}{$\mathrm{p}=0.003$} & $18.45 \pm 9.93$ & \multirow{3}{*}{$\mathrm{p}=0.012$} \\
\hline 30-45 Years & $11.77 \pm 10.1$ & & $11.81 \pm 9.72$ & & $11.08 \pm 10.18$ & \\
\hline$>46$ Years & $23.83 \pm 9.39$ & & $24.17 \pm 11.22$ & & $20.5 \pm 13.23$ & \\
\hline
\end{tabular}

Table 5:-The combined effect of three advice session (paired sample test)

\begin{tabular}{|l|l|l|l|}
\hline Effect & No & Yes & \multirow{2}{*}{$\mathrm{p}=0.039$} \\
\cline { 1 - 3 } Session 1 & 23 & 32 & \\
\cline { 1 - 3 } Session 2 & 27 & 28 & \\
\cline { 1 - 3 } Session 3 & 26 & 29 & \\
\hline
\end{tabular}

\section{Discussion:-}

This study is probably the first attempt to detect the effective use of Framingham risk score and advice in smoking cessation in Saudi Arabia. This step, if found effective, may help in reducing cardiovascular diseases and other smoking related issues including public health and economy.

The study was conducted among the males only; we did not include females because of social barriers and community reservations. The sample population is predominantly Saudi $(93.75 \%)$ because the study was conducted in a governmental hospital where most of the non-Saudis prefer the private hospitals.

Our results indicate that only 4 persons (16\%) of the intervention group quit smoking and 21 persons (84\%) did not and in the control group 2 persons did (6.6\%) while 28 persons (93.33\%) did not; also the decrease in the number of cigarettes after advice did not show significant values. There is no significant difference either in the duration of smoking between two groups nor in the number of cigarettes before the advice, which made these two groups equivalent to each other.Sitting with smokers shows high significant increase in the intervention group as compared to the control group, and we think that it could be one of the factors that affected our hypothesis in addition to other limitations.

We found that the main reason for quitting was health in both groups. The results show that the differences in marital status made no difference. The greatest effect in the first time period is referred to the short time between the advice and the follow up, so the smoker might be thinking about the advice in the first two weeks, then return to his usual habits later on. There was no advantage of using Framingham risk score and advice in quitting of smoking by the smokers for various reasons. 
The study shows age group of $>46$ years had the highest number of cigarettes per day and this may be attributed to social life and work stress. Another reason may be that they started smoking since they were young so, they became more strongly addicted. Also, we found that the age group (30-45 years) consumed the lowest number of cigarettes per day; because they may have greater awareness of the effect of smoking on their health, through the electronic media and Internet.We could not find any other similar study for the comparison of our findings.

\section{Conclusion:-}

Smoking is a harmful habit and our aim should be to quit it. We found that sharing Framingham Risk Score with the smokers did not have any significant effect. Other potential tools should also be used to test their efficacy for advice on quitting smoking. The data in our study are limited by small number. Further large scale investigations are needed to validate the accuracy of our results.

\section{Author Contribution:-}

Amr Jamal supervising and reviewing the team's work. Abdulaziz Alonazy Writing the literature, Methodology, Organise the references and put them in Vancouver style, organise the questionnaire and data collection. Rayan Alzuhairi Writing the literature, Methodology, organise the questionnaire and Data collection. Abdullah Aldubaib, Abdullah Alrajhi \& Abdulaziz Alsuwailem Collecting the literature review, collecting the questionnaire, Organise the questionnaire and Data collection.

\section{Acknowledgment:-}

The researchers are thankful to Family Medicine Department, Prof. HishamAbou-Auda, Prof. Riaz Qureshi, Dr. Mohammed Omran, Dr. TameemAlghanam, Prof. Ahmad Almandil, Dr. ShaikShaffi Ahmed and our colleague TareqAljurf for their comments, and help in analysis of the result and their guidance to complete the research.

\section{References:-}

1. Mallaina P, Lionis C, Rol H, Imperiali R, Burgess A, Nixon M, et al. Smoking cessation and the risk of cardiovascular disease outcomes predicted from established risk scores: results of the Cardiovascular Risk Assessment among Smokers in Primary Care in Europe (CV-ASPIRE) study. BMC public health. 2013;13:362.

2. Burford O, Jiwa M, Carter O, Parsons R, Hendrie D. Internet-based photoaging within Australian pharmacies to promote smoking cessation: randomized controlled trial. Journal of medical Internet research. 2013;15(3):e64.

3. Swan GE, McClure JB, Jack LM, Zbikowski SM, Javitz HS, Catz SL, et al. Behavioral counseling and varenicline treatment for smoking cessation. American journal of preventive medicine. 2010;38(5):482-90.

4. Rodgers A, Corbett T, Bramley D, Riddell T, Wills M, Lin RB, et al. Do u smoke after txt? Results of a randomised trial of smoking cessation using mobile phone text messaging. Tobacco control. 2005;14(4):255-61.

5. Valdivieso-Lopez E, Flores-Mateo G, Molina-Gomez JD, Rey-Renones C, Barrera Uriarte ML, Duch J, et al. Efficacy of a mobile application for smoking cessation in young people: study protocol for a clustered, randomized trial. BMC public health. 2013;13:704.

6. Diaz-Gete L, Puigdomenech E, Briones EM, Fabregas-Escurriola M, Fernandez S, Del Val JL, et al. Effectiveness of an intensive E-mail based intervention in smoking cessation (TABATIC study): study protocol for a randomized controlled trial. BMC public health. 2013;13:364

7. McClure JB, Shortreed SM, Bogart A, Derry H, Riggs K, St John J, et al. The effect of program design on engagement with an internet-based smoking intervention: randomized factorial trial. Journal of medical Internet research. 2013;15(3):e69.

8. Myung SK, Park JG, Bae WK, Lee YJ, Kim Y, Seo HG. Effectiveness of proactive Quitline service and predictors of successful smoking cessation: findings from a preliminary study of Quitline service for smoking cessation in Korea. Journal of Korean medical science. 2008;23(5):888-94.

9. Quitting Smoking Among Adults --- United States, 2001-2010

10. http://www.cdc.gov/mmwr/preview/mmwrhtml/mm6044a2.htm\#fig (accessed on 03 Nov, 2013)

11. Risk Assessment Tool for Estimating Your 10-year Risk of Having a Heart Attack.

12. http://cvdrisk.nhlbi.nih.gov/calculator.asp (accessed on 15 Oct, 2013)

13. Yusuf S, Hawken S, Ounpuu S, Dans T, Avezum A, Lanas F, McQueen M, Budaj A, Pais P, Varigos J, Lisheng L: INTERHEART Study Investigators: Effect of potentially modifiable risk factors associated with myocardial infarction in 52 countries (the INTERHEART study): case-control study. Lancet 2004, 364:937-952

14. Bassiony MM. Smoking in Saudi Arabia. Saudi Med J. 2009;30(7):876-81

15. Li Q, Hsia J, Yang G. Prevalence of Smoking in China in 2010. New England Journal of Medicine. 2011;364(25):2469-70 